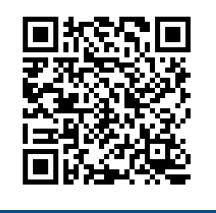

Keywords: Coagulant

Crystallinity

$\mathrm{NaOH} /$ urea

Regenerated cellulose membrane

Received 28/08/2018

Accepted 29/01/2019

Correspondence: szakaria@ukm.edu.my
Nyak Syazwani Nyak Mazlan ${ }^{\text {la }}$, Sarani Zakaria ${ }^{\text {lb+ }}$, Sinyee Gan ${ }^{2 a}$, Chia Chin Hua', Khairunnisa Waznah Baharin'

\section{COMPARISON OF REGENERATED CELLULOSE MEMBRANE COAGULATED IN SULPHATE BASED COAGULANT}

MAZLAN, N. S. N.; ZAKARIA, S.; GAN, S.; HUA, C. C.; BAHARIN, K. W. Comparison of regenerated cellulose membrane coagulated in sulphate based coagulant. CERNE, v. 25 , n. I, p. 18-24, 2019.

\section{HIGHLIGHTS}

Regenerated cellulose membrane (RCM) coagulated in distilled water has higher mechanical strength compare with membrane coagulated in other coagulant.

RCM coagulated in $\mathrm{H}_{2} \mathrm{SO}_{4}$ and $\left(\mathrm{NH}_{4}\right)_{2} \mathrm{SO}_{4}$ has the lower crystallinity index compared that coagulated in distilled water.

\section{ABSTRACT}

Regenerated cellulose properties can be altered and manipulated by various methods and procedures. Coagulation steps in cellulose regeneration process is one of the most crucial step in determining the final properties of the regenerated cellulose products. This study was conducted to investigate the effect of different type of coagulant on the properties of regenerated cellulose membranes (RCM). Hence, the coagulation mechanism will be highlighted and postulated. Cellulose from cotton linter was dissolved in $\mathrm{NaOH}$ / urea via precooled method to form cellulose solution and coagulated in three types of coagulant which were distilled water, $5 \mathrm{wt} \% \mathrm{H}_{2} \mathrm{SO}_{4}$ and $5 \mathrm{wt} \%\left(\mathrm{NH}_{4}\right)_{2} \mathrm{SO}_{4}$ which lead to the formation of RCM. The RCM were air dried and characterized for their physical, mechanical and chemical properties by using $X$-ray diffraction $(X R D)$, tensile and Fourier transform infrared (FTIR). Results showed that RCM coagulated in distilled water has the highest tensile strength and crystallinity index but showed the lowest value for the elongation at break. Meanwhile, the RCM coagulated in $5 \mathrm{wt} \%\left(\mathrm{NH}_{4}\right)_{2} \mathrm{SO}_{4}$ has the lowest tensile strength and crystallinity index but had the highest value of the elongation at break. From these results, the crystallinity of RCM has affected the elongation at break for all sample. RCM with higher crystallinity have lower elongation at break compared to the one with higher crystallinity. The RCM coagulated in $5 \mathrm{wt} \% \mathrm{H}_{2} \mathrm{SO}_{4}$ has intermediate results for all tensile strength, elongation at break and crystallinity compared to those coagulated in distilled water and $5 \mathrm{wt} \%\left(\mathrm{NH}_{4}\right)_{2} \mathrm{SO}_{4}$. 


\section{INTRODUCTION}

Lignocellulose biomass has been recognized as the most abundant organic material on earth. Lignocellulose consists of several components which are cellulose, hemicellulose, lignin and extractives (Ramamoorthy, 20I5). It has high potential to be used as a low cost starting material in the industrial process compared to petroleumbased materials. Various types of products are produced from lignocellulose biomass especially from cellulose. Cellulose is used to make products such as paper (Zhang et al. 2016), filter membrane (Makaremi et al., 20I5), film (Gan et al., 2017) and fabric (Woodings, 2016).

Cellulose is readily available and renewable material which are convenient to be used in products for daily life. Cellulose is considered a very unique material because of its complexity (Anuar et al., 2018). It consists of $D$-glucose units which are linked together at the $\beta$ (I-4) glycosidic bond. Cellulose structure is held together by inter - and intra hydrogen bond which provides stiffness and strength to the cellulose chain. Its amphiphilic properties also open wide opportunities for the researchers to use it for many new applications and products (Björn et al., 2017)

Dissolution of cellulose in most classical organic solvents has been a drawback in most of the study due to their properties as the semi-crystalline polymer. This has contributed to the cellulose chain rigidity due to the presence of large amount of intra- and intermolecular hydrogen bonding in cellulose (Glasser et al., 2012). Major solvents used for cellulose dissolution are ionic liquid (Liu et al. 2017), $\mathrm{N}$-methylmorpholine $\mathrm{N}$-oxide (NMMO) (Biganska et al., 20I2), LiCl-based (Khaliq and Kim, 2016) and phosphoric acid- based (Douglass et al. 20I6). These solvents are widely used in industry but some of them are not eco-friendly such as the release of toxic gas. Furthermore their chemical waste cannot be recycled and caused pollution to the ecosystems. Later, the economical and eco-friendly alkali-urea was developed by Zhou and Zhang (2000), which has opened many opportunities for the development of other cellulose based products. Lue and his colleagues had explained the formation of the inclusion complex during cellulose dissolution using $\mathrm{LiOH} /$ urea solvent (Lue et al., 2007). During the cellulose dissolution process, cellulose started to swell and formed ballooning structure. Then, the inclusion complex formed around the cellulose chain and enable the cellulose bundle to separate from one and another to form single cellulose chain (Tanvir et al., 20 I7; Björn et al. 2017).

Regenerated cellulose is the product formed after dissolved cellulose being regenerated back into cellulose in the form of cellulose II (Singh et al., 20I5). After intraand intermolecular hydrogen bonds in the cellulose are destroyed by $\mathrm{NaOH} / \mathrm{urea}$, the regeneration of cellulose is completed by coagulation process where the cellulose chains reform into crystalline cellulose structure. But, the properties of regenerated cellulose are not like those of native cellulose as the crystallinity and cellulose arrangement have been disturbed (Lindman et al., 20I7).

Coagulation is a process to form regenerated cellulose. It can also be understood as dehydration or neutralization of the cellulose solution. Several types of coagulant have been used for the preparation regenerated cellulose such as acid-based (Blachechen et al., 2014), sulphate-based (Azahari et al., 2017; Ruan et al., 2004), water (Li et al., 20I2) and alcohol (Ergün, 20l4). During coagulation process, phase separation occurs between cellulose solution and the coagulant. Different concentration between coagulant and cellulose solution will cause the solvent to diffuse out and non-solvent to diffuse into the membrane (Wang et al. 2017). Diffusion between cellulose solution and coagulant will occur to achieve the equilibrium point (Makarova et al., 2016). This also causes neutralization in the regenerated cellulose. Types of coagulant used will affect the chemical, physical and mechanical properties of the regenerated cellulose products.

Each coagulant used will form different properties of regenerated cellulose membrane. For example, cellulose solution that coagulated with increasing concentration of sulphuric acid $\left(\mathrm{H}_{2} \mathrm{SO}_{4}\right)$ produced a membrane with smaller pore size (Zhang et al., 2005). But, higher concentration of acid will cause degradation of cellulose, hence reduce the mechanical properties of the membrane (Fu et al., 20I4). Other than that, it is reported that ammonium sulphate $\left(\left(\mathrm{NH}_{4}\right)_{2} \mathrm{SO}_{4}\right)$ has been used as a coagulant (Ruan et al., 2004). Ruan et al (2004) have proposed that the interaction between ammonium sulphate and cellulose solution caused hydrogen ions in solution to react with hydroxide in the solvent. They also stated that ammonia act as pore former during the mechanism of cellulose regeneration. They reported that as the concentration of ammonium sulphate increases, the pore size of the regenerated cellulose membrane also increases. These two coagulants present a contrary effect on the membrane's pore size when the concentration of the coagulant is increased. Therefore, in this study, the crystallinity and mechanical properties of RCM that coagulated in distilled water, sulphuric and ammonium sulphate were compared and analysed. The main objectives of this study are to compare the driving force for coagulation process by explaining the mechanism and the effect of different type of coagulant used during the regeneration of cellulose membrane process. 


\section{MATERIAL AND METHODS}

Pure cotton linter pulp with an average molecular weight (Mn) $9 \times 10^{4}$ was supplied by Hubei Chemical Fiber (Xiangfan, China). $98 \%$ analytical grade sodium hydroxide $(\mathrm{NaOH})$, urea, ammonium sulphate $\left(\left(\mathrm{NH}_{4}\right) 2 \mathrm{SO}_{4}\right)$ and sulphuric acid $\left(\mathrm{H}_{2} \mathrm{SO}_{4}\right)$ were purchase from $\mathrm{R} \& M$ Chemicals. All chemicals were used without any further purification.

\section{Preparation of regenerated cellulose membrane}

Cellulose solvent of $\mathrm{NaOH} /$ urea/distilled water at a weight ratio of 7:12:81 was prepared and frozen for 12 h. The cellulose solvent then was thawed to $-13^{\circ} \mathrm{C}$ (Gan et al., 2017) and $5 w t \%$ of cotton linter was added into the solvent and stirred for $5 \mathrm{~min}$ to form a transparent cellulose solution. The cellulose solution was centrifuged at 8,000 $\mathrm{rpm}, 5^{\circ} \mathrm{C}$ for $5 \mathrm{~min}$ to remove air bubble and separated the dissolved cellulose and the undissolved (Kaco et al., 2017). All of the coagulation process was performed at room temperature and the cellulose solution used for each coagulant came from the same batch in order to minimize error. The cellulose solution was cast on a glass plate and coagulated for $5 \mathrm{~min}$ in different types of coagulant of distilled water, $5 \mathrm{wt} \% \mathrm{H}_{2} \mathrm{SO}_{4}$ and $5 \mathrm{wt} \%\left(\mathrm{NH}_{4}\right)_{2} \mathrm{SO}_{4}$ and coded as RCM-0, RCM-5H and RCM- $5 \mathrm{~N}$ respectively. The coagulation time and coagulant temperature were kept constant Distilled water was used as control coagulant for further comparison on the effect of coagulant in the regenerated membrane formed. Regenerated cellulose membrane was then neutralized in distilled water for 3 days to remove excess solvent and air dried for characterization.

\section{Characterization}

\section{FTIR}

Regenerated cellulose membranes were analysed using Attenuated Total Reflectance-Fourier Transform Infrared Spectroscopy (ATR-FTIR) (Perkin Ekmer Spectrum 400 FT-IR). This spectroscopy was used to identify the functional group presented in the RCM. The film samples were analysed at wavenumber 4000-800 $\mathrm{cm}^{-1}, 32$ scans and $4 \mathrm{~cm}^{-1}$ resolutions

\section{X-ray diffraction}

Crystallinity index $(\mathrm{Crl})$ and crystal phase of raw cotton linter and the regenerated cellulose membranes were characterized by X-ray diffraction (XRD) (Bruker Axs D8 Advance, Germany) (Yan et al., 2017). The XRD was conducted using radiation of $\mathrm{Cu} \mathrm{Ka}=1.5458 \AA$ at a diffraction angle of $(2 \theta)$ range from 5 to $60^{\circ}$. The crystallinity indexes of the cellulose and regenerated cellulose were calculated using Equation I, $A_{\text {Crystal }}$ is the sum area under crystalline diffraction peak and $A_{\text {Total }}$ is the total area under the diffraction curve.

$$
\operatorname{CrI}(\%)=\frac{\text { ACrystal }}{\text { ATotal }} \cdot 100
$$

Tensile test

The dried regenerated cellulose membranes were cut into $\mathrm{I} \times 8 \mathrm{~cm}$ for tensile measurement using a Universal testing machine (GOTECH, model Al3000 ) equipped with a $100 \mathrm{~N}$ load cells. The crosshead speed used for this analysis was $10 \mathrm{~mm} / \mathrm{min}$. Testing was conducted by using at least five strips of the membrane and the average value was recorded for accuracy.

\section{RESULTS AND DISCUSSION}

Figure I shows the FTIR spectrum of regenerated cellulose membrane. Two new peaks appeared on RCM$0, \mathrm{RCM}-5 \mathrm{H}$ and RCM-5N at wavenumbers of 3495 and $3445 \mathrm{~cm}_{-1}$ representing stretching of hydrogen bonds. The peak at $164 \mathrm{I} \mathrm{cm}^{-1}$ representing $\mathrm{C}-\mathrm{O}$ carbonyl stretching vibrations, $\mathrm{O}-\mathrm{H}$ bending vibration at 1313 and $1366 \mathrm{~cm}^{-1}$ and a sharp peak at $894 \mathrm{~cm}^{-1}$ representing the C-O-C bridge stretching of $\beta$-glycosidic linkage between glucose in cellulose chain (Tanvir et al., 2017). Higher intensity at 894 $\mathrm{cm}^{-1}$ indicating higher amorphous region in the regenerated cellulose membrane (cellulose II) than in cotton (cellulose I) (Liu et al. 2010) These absorption band were only presented in regenerated cellulose membrane (Tanvir et al., 20I7). Peak $333 \mathrm{I} \mathrm{cm}^{-1}$ has shifted to the right suggesting that the regenerated membrane has stronger inter- and intra-molecular hydrogen bond. This finding also supports for the higher value for elongation at break of regenerated cellulose membranes (Zhang et al., 20II). The peak at $2891 \mathrm{~cm}^{-1}$ indicated that there were few interactions between $\mathrm{CH}, \mathrm{CH}_{2}$ and other chemical components. It also suggested that the membrane has compact structure compared to raw cellulose and the crystallinity had been destroyed during regeneration (Cai et al., 2007; Shuai et al., 2009; Tang et al., 20I I).

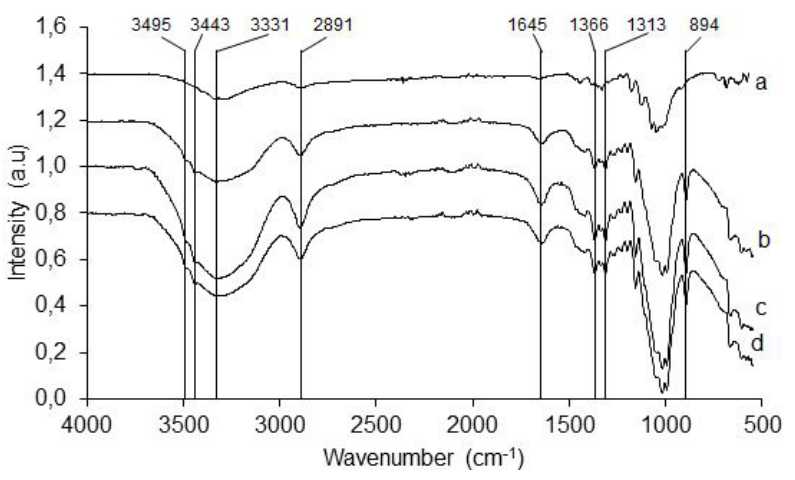

FIGURE I FTIR spectra of regenerated cellulose membrane a) Raw cotton linter, b) RCM-0, c) RCM-5H and d) RCM-5N. 
Table I shows the crystallinity index $(\mathrm{Crl})$ of native cotton linter and the regenerated cellulose. XRD diffractogram on figure 2 was analysed by focusing at peak $2 \theta=12.1,20.3$, and $21.8^{\circ}$ are corresponding to the (II0), (II0), and (200) planes of cellulose II crystalline, respectively (Zeng et al. 20I I). The diffractogram showed that the crystallinity of cellulose membrane regenerated in distilled water is $45.4 \%$ while membrane regenerated in sulphuric acid and ammonium sulphate are $43.7 \%$ and $42.5 \%$ respectively and the crystallinity of native cotton linter was $73 \%$ as reported by Oun and Rhim (2015).

TABLE I Crystallinity index of regenerated cellulose membrane.

\begin{tabular}{ccc}
\hline Sample & Crl (\%) & Reference \\
\hline Raw cotton linter & 73.0 & Oun \& Rhim 20I5 \\
RCM-0 & 45.4 & This study \\
RCM-5H & 43.7 & This study \\
RCM-5N & 42.5 & This study \\
\hline
\end{tabular}

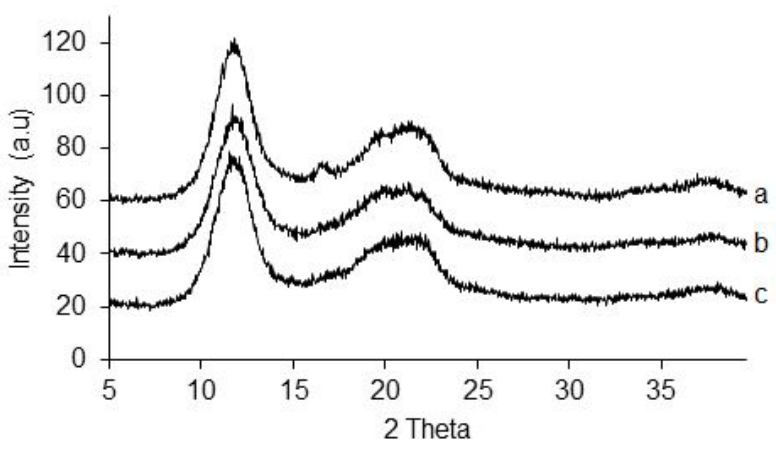

FIGURE 2 XRD diffractogram of a) RCM-0, b) RCM-5H and c) RCM-5N

Lower crystallinity could be caused by the disturbance at the crystalline area of samples during cellulose dissolution and regeneration process. As reported, the crystallinity of native cellulose was destroyed during cellulose dissolution process (Fu et al., 2017; Kaco et al., 20I4; Li et al., 20I5; Lue et al., 2007). In the dissolution and regeneration process, cellulose tends to aggregate back to its crystalline structure by forming different types of bonding which were van der Waals, hydrophobic and inter- and intramolecular hydrogen bonding (Gan et al., 2017). Different coagulant type contributes to the regeneration of organizing crystalline structure. RCM with lower crystallinity imply lower percentage of bonding. This is because the crystalline region in the native cellulose had been destroying during the dissoution process (Mohamed et al., 2016).

$\mathrm{RCM}$ formed by coagulating in $\mathrm{H}_{2} \mathrm{SO}_{4}$ and $\left(\mathrm{NH}_{4}\right)_{2} \mathrm{SO}_{4}$ had lower $\mathrm{Crl}$ compared to coagulated in distilled water because the neutralization of the solvent and nonsolvent in the system was slower compare to the solidification process of the membrane (lin et al. 2010). The lower crystallinity value for RCM has also proven that they do not possess similar properties as the native cellulose.
The tensile strength and elongation at break of the membranes were illustrated in figure 3 and figure 4 respectively. The results showed that different types of coagulant used to regenerate cellulose did affect their mechanical properties where the tensile strength for RCM0, RCM-5H and RCM-5N are 34.23, 27.24, and 24. $15 \mathrm{MPa}$ respectively, while the elongation at break for each sample are 4.08, 12.04 and I5.09\% respectively. The membrane that coagulated in distilled water has the highest tensile properties, but its elongation at break was the lowest.

Tensile strength at break

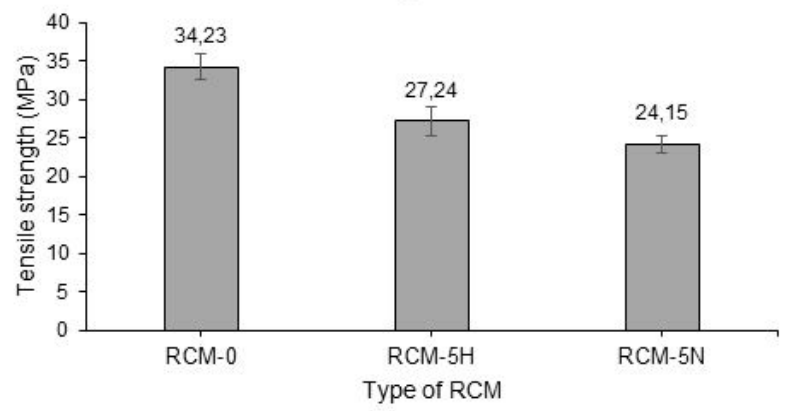

FIGURE 3 The tensile strength of regenerated cellulose membranes. RCM- 0 in distilled water RCM- $5 \mathrm{H}$ in $5 \mathrm{wt} \% \mathrm{H}_{2} \mathrm{SO}_{4}$ and $\mathrm{RCM}-5 \mathrm{~N}$ in $5 \mathrm{wt} \%\left(\mathrm{NH}_{4}\right)_{2} \mathrm{SO}_{4}$.

Elongation at break

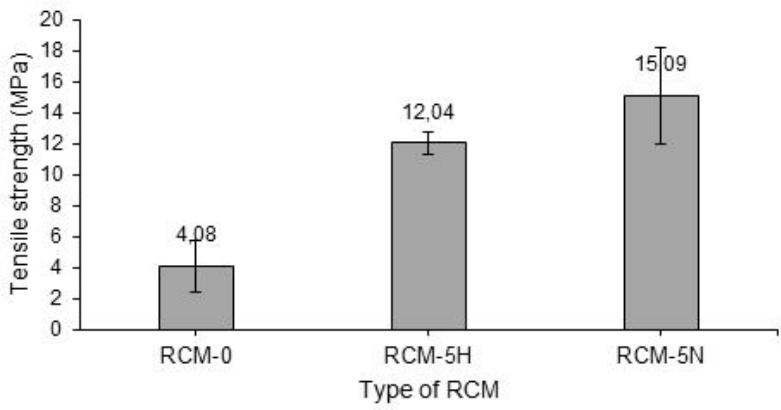

FIGURE 4 Elongation at break of regenerated cellulose membrane.

Higher tensile value suggests that the membrane possessed with stronger inter- and intra-molecular hydrogen bonding (Fu et al., 20l4). During regeneration of cellulose in distilled water, the cellulose solution coagulated slowly and homogeneously due to lower differences of coagulant concentration which contributed to the phase separation (Li et al., 20 I2). It also contributed to the compact structure of regenerated membrane (Fu et al., 2014) which was supported by the value calculated for the crystallinity of the membrane.

Sulphuric acid possesses $\mathrm{H}^{+}$cations which are the key component to trigger neutralization reaction of the membrane and it also has higher concentration difference compared to distilled water/cellulose solution (Zhang et al., 2009). Although the coagulation process using sulphuric 
acid has speed up the regeneration process due to fast interchanges between cellulose solvent and coagulant, however, acidic media could lead to cellulose degradation ( $\mathrm{Fu}$ et al., 20I4). Moreover, higher acid or alkali concentration can be corrosive and tends to destroy its surrounding materials. Other than that, the molecular weight of the coagulant used also contribute to the final properties of RCM. In this case, $\mathrm{H}_{2} \mathrm{SO}_{4}$ has a lower molecular weight compared to $\left(\mathrm{NH}_{4}\right)_{2} \mathrm{SO}_{4}$. Smaller molecular weight makes the counter diffusion between solvent and non-solvent to be easier and faster. This also effects on crystallinity, pore size and mechanical strength. When the coagulation rate increases, the rate of diffusion between solvent and nonsolvent also increases. This leads to the large pore size of the regenerated cellulose membrane (Zhang et al., 2009).

On the other hand, ammonium sulphate, a pure salt system, causes the formation of regenerated cellulose to be slightly slower than when using acid due to its larger molecular weight. Therefore, the membrane formed possesses better elongation at break, showed an increased by $3.05 \%$ compared to the membranes coagulated in sulphuric acid (Zhang et al., 2009). Lower regeneration rate allows the cellulose macromolecules to aggregate in right order simultaneously and forms stronger inter- and intra-hydrogen bond within the cellulose chain. Stronger bonding between the cellulose in the system created a membrane with higher elongation percentage. But they also give a major drawback which increases the membrane stiffness and causes having lower mechanical strength as shown in figure $I$ and figure 2. Other than that, the reason for these phenomena has not been resolved elsewhere.

\section{CONCLUSION}

Type of coagulant affected the mechanical properties of the regenerated cellulose membranes. Tensile strength of RCM were the highest when coagulated in distilled water and the lowest when coagulated in $\left(\mathrm{NH}_{4}\right)_{2} \mathrm{SO}_{4}$. Meanwhile, the value for elongation at break was vice versa compared to tensile strength results. $\mathrm{RCM}$ coagulated in $\mathrm{H}_{2} \mathrm{SO}_{4}$ and $\left(\mathrm{NH}_{4}\right)_{2} \mathrm{SO}_{4}$ has the lower crystallinity index compared that coagulated in distilled water. Based on this study, RCM coagulated in $\mathrm{H}_{2} \mathrm{SO}_{4}$ have higher crystallinity index effects on the rearrangement of cellulose during coagulation process compared to the one coagulated in $\left(\mathrm{NH}_{4}\right)_{2} \mathrm{SO}_{4}$ even though similar weight percentage of chemical were used during coagulant preparation. Uniform networking of regenerated cellulose contribute to the RCM properties. These properties and characteristic can be alter by changing the type of coagulant use for RCM formation.

\section{ACKNOWLEDGEMENT}

The authors gratefully acknowledge to Universiti Kebangsaan Malaysia for financial support via research project grants DIP-20I8-033. The authors are also thankful to the Centre for Research and Instrumentation Management (CRIM), UKM for providing XRD testing.

\section{REFERENCES}

ANUAR, N. I. S.; ZAKARIA, S.; KACO, H.; HUA, C. C.; CHUNHONG, W.; ABDULLAH, H. S. Physico-mechanical, chemical composition, thermal degradation and crystallinity of oil palm empty fruit bunch, kenaf and polypropalene fiber: A comparative study. Sains Malaysiana, v. 47, n. 4, p. 839-85I, 2018 .

AZAHARI, N. A.; ZAKARIA, S.; KACO. H.; GAN, S.; CHIA, C. H.; JAAFAR, S. N. S.; SAJAB, M. S. Regenerated kenaf cellulose membrane from $\mathrm{NaOH}$ /urea aqueous solution by coagulating with sulphuric acid. Sains Malaysiana, v. 45, n. 5, p. 795-801, 2017.

BAHARIN, K. W.; ZAKARIA, S.; ELLIS, A. V.; TALIP, N.; KACO, H.; GAN, S.; ZAILAN, F. D.; HASHIM, A. S. S. N. Factors affecting cellulose dissolution of oil palm empty fruit bunch and kenaf pulp in $\mathrm{NaOH} /$ urea solvent. Sains Malaysiana, v. 47 , n. 2 , p. $377-386,2018$.

BIGANSKA, O.; NAVARD, P.; BIGANSKA, O.; NAVARD, P. Morphology of cellulose objects regenerated from cellulose-N-methylmorpholine $\mathrm{N}$-oxide-water solutions. Cellulose, v. 16, n. 2, p. 179-188, 2009.

BJŐRN, L.; BRUNO, M.; LUIS, A.; CAROLINA, C.; HÅKAN, E.; MAGNUS, N. The relevance of structural feature of cellulose and its interactions to dissolution, regeneration, gelation and plasticization phenomena. Physical Chemistry Chemical Physic, v. 19, n. 35, p.2370423718, 2017

BLACHECHEN, L. S.; FARDIM, P.; PETRI, D. F. S. Multifunctional cellulose beads and their interaction with gram positive bacteria. Biomacromolecules, v. 15, n. 9, p. 3440-3448, 2014.

CAI, J.; WANG, L.; ZHANG, L. Influence of coagulation temperature on pore size and properties of cellulose membranes prepared from $\mathrm{NaOH}$ - urea aqueous solution. Cellulose, v. 14, p. 205-2I5, 2007.

DE SILVA, R.; VONGSANGA, K.; WANG, X.; BYRNE, N. Understanding key wet spinning parameters in an ionic liquid spun regenerated cellulosic fibre. Cellulose, v. 23, n. 4, p. $274 \mid-275 I, 2016$.

DOUGLASS, E. F.; AVCI, H.; BOY, R.; ROJAS, O. J.; KOTEK, R. A Review of Cellulose and Cellulose Blends for Preparation of Bio-derived and Conventional Membranes, Nanostructured Thin Films, and Composites. Polymer Reviews. v. 0, n. 0, p.I-62, 2016. 
ERGÜN, E. G. Film Fabrication Using Corncob ss Lignocellulosic. 2014. 55 p. MSc thesis Middle East Technical University, Turkey, 2014.

FU, F.; GU, J.; XU, X.; XIONG, Q.; ZHANG, Y.; LIU, X.; ZHOU, J. Interfacial assembly of $\mathrm{ZnO}$-cellulose nanocomposite films via a solution process: a one-step biomimetic approach and excellent photocatalytic properties. Cellulose, v.24, n. I, p. I47-I62, 2017.

FU, F.; GUO, Y.; WANG, Y.; TAN, Q. Structure and properties of the regenerated cellulose membranes prepared from cellulose carbamate in $\mathrm{NaOH} / \mathrm{ZnO}$ aqueous solution. Cellulose. v.21, p.2819-2830, 2014.

GAN, S.; ZAKARIA, S.; CHIA, C. H.; CHEN, R. S.; ELLIS, A. V.; KACO, H. Highly porous regenerated cellulose hydrogel and aerogel prepared from hydrothermally synthesized cellulose carbamate. PLoS ONE, v. I2, n. 3, p. I-13, 2017.

GAN, S.; ZAKARIA, S.; JAAFAR, S. N. S. Enhancement of hydrothermal carbamated cellulose nanocomposite films reinforced with graphene oxide. Carbohydrate Polymer, v. I72, p. 284-293, 2017.

GLASSER, W. G.; ATALLA, R. H.; BLACKWELL, J.; BROWN, R. M.; BURCHARD, W.; FRENCH, A. D.; KLEMM, D. O.; Nishiyama, Y. Erratum to: About the structure of cellulose: Debating the Lindman hypothesis. Cellulose, v.19, p.599, 2012.

JIN, Z.; WANG, S.; WANG, J.; ZHAO, M. \& GAO, S. Effect of Coagulation Bath Conditions on the Properties of Cellulose Packaging Films From lonic Liquid [ BMIM] Cl p. I I8-I20, 2010. Nome do periodico

KACO, H.; BAHARIN, K. W.; ZAKARIA, S.; CHIA, C. H.; SAJAB, M. S.; JAAFAR, S. N. S.; GAN, S. Preparation and characterization of $\mathrm{Fe}_{3} \mathrm{O}_{4} / \mathrm{SiO}_{2} /$ APTES core-shell nanoparticles. Sains Malaysiana, v. 46, n. 4, p. I2-14, 2017.

KACO, H.; ZAKARIA, S.; RAZALI, N. F.; CHIA, C. H.; ZHANG, L.; JANI, S. M. Properties of cellulose hydrogel from kenaf core prepared via pre-cooled dissolving method. Sains Malaysiana, v. 43, n. 8, p.1221-1229, 2014.

KHALIQ, Z.; KIM, B. C. Molecular characterization of thermoreversibility and temperature dependent physical properties of cellulose solution in N,N-dimethylacetamide and lithium chloride. Macromolecular Research, v.24, n.6, p.547-555, 2016.

LI, R.; WANG, S.; ANG, L.; LINA, Z. Dissolution of cellulose from different sources in an $\mathrm{NaOH} /$ urea aqueous system at low temperature. Cellulose, v.22, n. I, p.339-349, 2015.

LI, R.; ZHANG, L.; XU, M. Novel regenerated cellulose films prepared by coagulating with water: Structure and properties. Carbohydrate Polymers, v.87, n. I, p 95-100, 2012.
LINDMAN, B.; MEDRONHO, B.; ALVES, L.; COSTA, C.; EDLUND, H.; NORGREN, M. The relevance of structural features of cellulose and its interactions to dissolution, regeneration, gelation and plasticization phenomena. Physical Chemistry Chemical Physics, v.19, n.35, p. 23704-23718, 2017.

LIU, S.; ZENG, J.; TAO, D.; ZHANG, L. Microfiltration performance of regenerated cellulose membrane prepared at low temperature for wastewater treatment. Cellulose v.17, n.6, p.II59-1169, 2010.

LIU, Y.; JIANG, Z.; MIAO, J.; YU, Y.; ZHANG, L. Properties of flame-retardant cellulose fibers with ionic liquid. Fibers and Polymers, v. 18, n.5, p.915-921, 2017.

LUE, A.; ZHANG, L.; RUAN, D. Inclusion Complex Formation of Cellulose in $\mathrm{NaOH}-T h i o u r e a$ Aqueous System at Low Temperature. Macromolecular Chemistry and Physics, v.208, n.2I, p.2359-2366, 2007.

LUNDAHL, M. J.; CUNHA, A. G.; ROJO, E.; PAPAGEORGIOU, A. C.; RAUTKARI, L.; ARBOLEDA, J. C.; ROJAS, O. J. Strength and Water Interactions of Cellulose Filaments Wet-Spun from Cellulose Nanofibril Hydrogels. Scientific Reports, v. 6, p.I-13, 2016.

MAKAREMI, M.; DE SILVA, R. T.; PASBAKHSH, P. Electrospun nanofibrous membranes of polyacrylonitrile/halloysite with superior water filtration ability. Journal of Physical Chemistry C, v.I19, n. I4, p.7949-7958, 2015.

MAKAROVA, V. V.; ANTONOV, S. V.; BRANTSEVA, T. V.; KULICHIKHIN, V. G.; ANOKHINA, T. S. Phase-equilibrium and cellulose-coagulation kinetics for cellulose solution in $\mathrm{N}$-Methylmorpholine-N-oxide. Natural polymer, v.58, n.5, p.732-743, 2016.

MOHAMED, F.; HASBULLAH, H.; JAMI'AN, W. N. R.; SALLEH, W. N. H. W.; IBRAHIM, N.; ALI, R. R. Effect of coagulant bath on the gas permeation properties of cellulose acetate asymmetric membrane. IOP Conference Series: Earth and Environmental Science, v. 36, n. I, p.I-6, 2016.

OUN, A. A.; RHIM, J. W. Effect of post-treatments and concentration of cotton linter cellulose nanocrystals on the properties of agar-based nanocomposite films. Carbohydrate Polymers, v. I34, p. 20-29, 2015.

OUN, A. A.; RHIM, J. W. Effect of post-treatments and concentration of cotton linter cellulose nanocrystals on the properties of agar-based nanocomposite films. Carbohydrate Polymers, v. I34, p.20-29, 2015

RAHIM, S. N. A.; ZAKARIA, S.; JAAFAR, S. N. S.; CHIA, C. H.; ROSLAN, R.; KACO, H.; GAN, S. As-spun Bio-novolac Fibre Morphological Study based on Resin's Physicochemical Properties. Sains Malaysiana, v.46, n.9, p. I6591665, 2017. 
RAMAMOORTHY, S. K. Properties and Performance of Regenerated Cellulose Thermoset. 2015. 5 p. PhD thesis Swedish Centre for Resource Recovery University of Borås, Sweden, 2015.

RUAN, D.; ZHANG, L.; MAO, Y.; ZENG, M.; LI, X. Microporous membranes prepared from cellulose in $\mathrm{NaOH}$ /thiourea aqueous solution. Journal of Membrane Science, v. 24I, n. 2, p.265-274, 2004.

SHUAI, Z.; FA-XUE, L.; JIAN-YONG, Y.; LI-XIA, G. Coagulation studies of cellulose / $\mathrm{NaOH} /$ thiourea / urea / $\mathrm{H}_{2} \mathrm{O}$ fiber spinning system. e-Polymers, v.9, n.098, p. I-13, 2009.

SINGH, P.; DUARTE, H.; ALVES, L.; ANTUNES, F.; MOIGNE, N. LE; DORMANNS, J.; DUCHEMIN, B.; STAIGER, M. P.; MEDRONHO, B. From Cellulose Dissolution and Regeneration to Added Value Applications - Synergism Between Molecular Understanding and Material Development. Cellulose-Fundamental Aspects and Current Trends, p. I-44, 2015.

TANG, H.; CHANG, C.; ZHANG, L. Efficient adsorption of $\mathrm{Hg} 2+$ ions on chitin/cellulose composite membranes prepared via environmentally friendly pathway. Chemical Engineering Journal, v. 173, n.3, p.689-697, 201 I.

TANVIR, A.; AL-MAADEED, M. A.; HASSAN, M. K. Secondary chain motion and mechanical properties of $Y$-irradiated-regenerated cellulose films. Starch/Staerke, v. 69, p. I-8, 2017.

WANG, W.; LI, F.; YU, J.; ZHOU, J.; WANG, H. Effects of coagulation conditions on structure and properties of cellulose-based fibers from aqueous $\mathrm{NaOH}$ solvent. Carbohydrate Polymers, v.164, p.118-126, 2017.

WITTMAR, A.; VORAT, D.; ULBRICHT, M. Two step and one step preparation of porous nanocomposite cellulose membranes doped with $\mathrm{TiO}_{2}$. RSC Advance. v. 5, n. 107, p. 88070-88078, 2015.
WOODINGS, C. Cellulose Fibers, Regenerated. Encyclopedia of Polymer Science and Technology, 2016.

YAN, E. Y. C.; ZAKARIA, S.; CHIA, C. H.; BOKU, T. R. Bifunctional regenerated cellulose membrane containing $\mathrm{TiO}_{2}$ nanoparticles for absorption and photocatalytic decomposition. Sains Malaysiana, v. 46, n. 4, p. 637-644, 2017.

YLIANNALA, H. SOLUBILITY OF ENZYME-TREATED CELLULOSE IN AQUEOUS. Tampere University of Technology. 2016.

ZENG, J.; LI, R.; LIU, S.; ZHANG, L. Fiber-like TiO2nanomaterials with different crystallinity phases fabricated via a green pathway. ACS Applied Materials and Interfaces, v.3, n.6, p.2074-2079, $201 \mathrm{l}$.

ZHANG, L.; LIU, S.; ZHANG, L. Effects of polymer concentration and coagulation temperature on the properties of regenerated cellulose films prepared from LiOH / urea solution. Cellulose, v. 16, p. I89-198, 2009.

ZHANG, L.; MAO, Y.; ZHOU, J.; CAI, J. Effects of Coagulation Conditions on the Properties of Regenerated Cellulose Films Prepared in $\mathrm{NaOH} /$ Urea Aqueous Solution, p. 522529, 2005.

ZHANG, S.; FU, C.; LI, F.; YU, J.; GU, L. Direct Preparation of a Novel Membrane from Unsubstituted Cellulose in $\mathrm{NaOH}$ Complex Solution, Iranian Polymer Journal, v.18, n.10, p.767-776, 2009.

ZHANG, S.; LI, F.X.; YU, J.Y. Rheological properties of cellulose$\mathrm{NaOH}$ complex solutions: From dilute to concentrated states. Cellulose Chemistry and Technology, v. 45, n. 5 , p. $3|3,201|$

ZHANG, W.; JING, Z.; SHAN, Y.; GE, X.; MU, X.; JIANG, Y.; LI, H.; WU, P. Paper reinforced with regenerated cellulose: a sustainable and fascinating material with good. Journal of Materials Chemistry A: Materials for energy and sustainability, v. 4, p. 17483-17490, 2016. 